\title{
Vertical migratory behaviour of the euphausiid, Meganyctiphanes norvegica, and its dispersion in the Kattegat Channel
}

\author{
G. A. Tarling ${ }^{1}$, J. B. L. Matthews ${ }^{1}$, R. Saborowski ${ }^{2}$ \& F. Buchholz ${ }^{2}$ \\ ${ }^{1}$ Scottish Association for Marine Science, PO Box 3, Oban, Argyll, PA34 4AD, U.K \\ ${ }^{2}$ Biologische Anstalt Helgoland, Meeresstation, Postfach 180, D-27483 Helgoland, Germany
}

\begin{abstract}
The euphausiid Meganyctiphanes norvegica (Northern Krill) is predominantly an oceanic species common to the North Atlantic and adjacent seas. In the Kattegat the species concentrates in a series of depressions in the Kattegat Channel east of the island of Læs $\varnothing$ which represent havens of marine conditions beneath the low salinity Baltic outflow.

The vertical migratory behaviour of Meganyctiphanes results in it encountering considerable contrasts in physical conditions during its diurnal cycle. This behaviour and the resulting physical experience of the animals were investigated by means of a combination of net sampling and ADCP transects across the Alkor Deep (131 m) in summer (18-19/7/96) and winter (9-10/3/97).

In both summer and winter the krill tended to concentrate within the basin during daytime and to disperse in the upper layers at night. The period of dispersion was longer in winter $(17.00-05.00 \mathrm{~h})$ than in summer $(23.00$ $02.00 \mathrm{~h}$ ). The complex layering of different wind-induced and tidal current systems acted to advect the krill away from the basin during their upward phase at night. ADCP measurements showed that in summer the krill would be advected SSW at an average rate of $3 \mathrm{~cm} \mathrm{~s}^{-1}$, but that in winter they would be advected WSW at $3.2 \mathrm{~cm}$ $\mathrm{s}^{-1}$. Calculations show that the krill would be capable of swimming against such currents without increasing their standard metabolism and that their distribution in the vicinity of the basin seems to be determined more by biotic than by abiotic factors.
\end{abstract}

\section{Introduction}

Meganyctiphanes norvegica is an important part of the Atlantic pelagic community as it is the largest euphausiid species in the northern hemisphere, eats predominantly zooplankton but also phytoplankton as energy sources and is itself a staple food of vertebrates, particularly fish, birds and whales (Pearcy et al., 1979). The species is found within a temperature range of $2-15{ }^{\circ} \mathrm{C}$ (Einarsson, 1945; Lindley, 1982) and occurs within a wide geographic area from the east coast of Canada to western Europe, including the Mediterranean and regions of the Arctic. Accordingly, it is expected that the species exhibits specific behavioural and physiological adaptations that allow it to inhabit a wide range of different oceanographic regimes. The Kattegat represents an extremity in the species' distributional range because it is influenced by two contrasting water bodies, a brackish input from the Baltic and a marine input from the Skagerrak. The physiological tolerances and behavioural adaptations exhibited by krill in this region would be expected to be close to their limits of tolerance, and study of this population will produce insights into which processes are able to adapt and in what ways.

Within the northern Kattegat, the species is found mainly in the basins which represent havens of marine conditions beneath freshwater outflow in the surface layers. As with many euphausiid species (Mauchline \& Fisher, 1969; Mauchline, 1980), M. norvegica typically exhibits a pronounced diurnal vertical migratory pattern in the Kattegat (Buchholz et al., 1995) where the species ascends to upper layers during the night and descends during the day. Given the contrasting directions of the marine inflow and the freshwater outflow within the region as well as the variable effect 


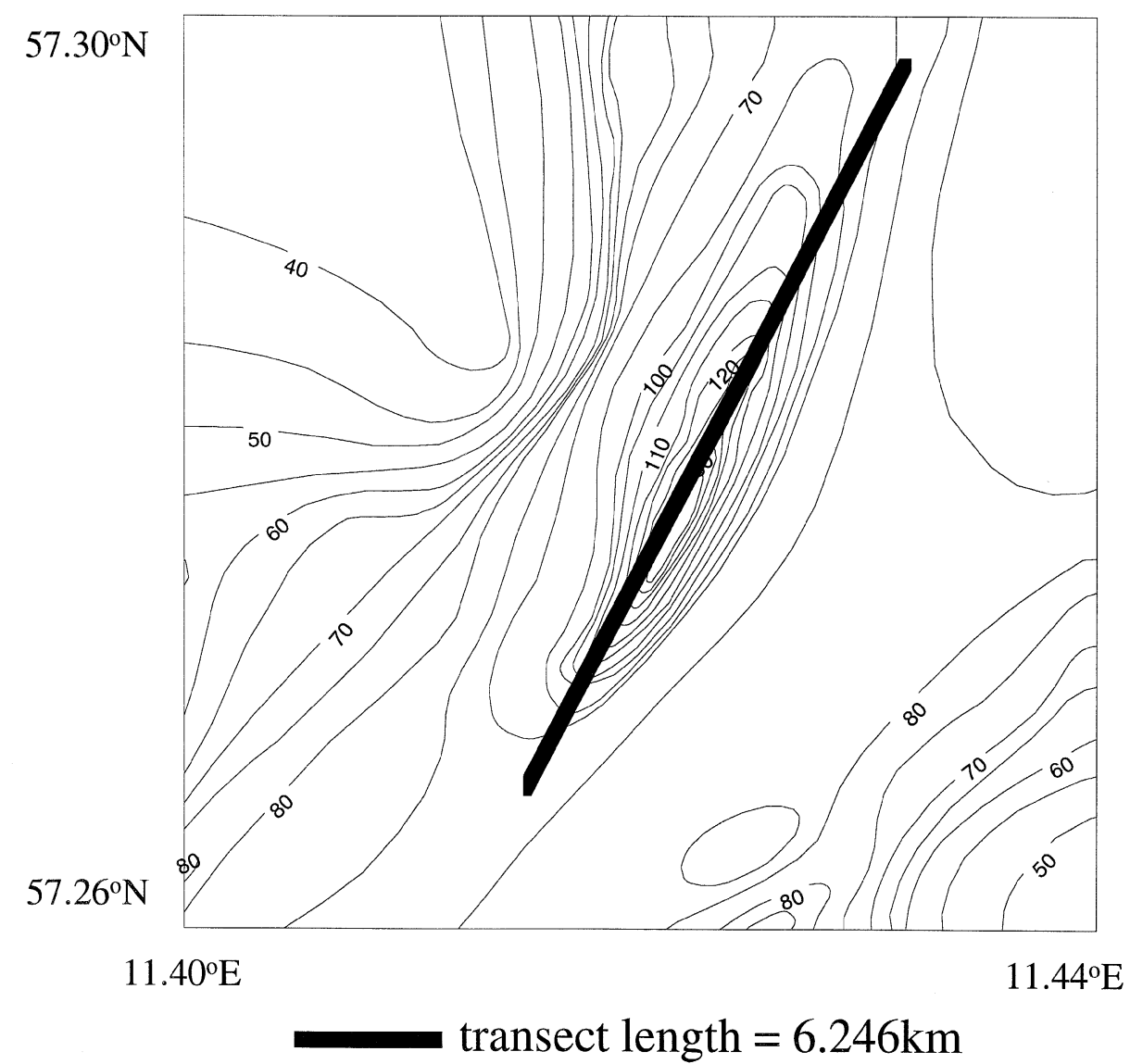

Figure 1. The Alkor Deep showing the net sampling transect.

of tide and wind on current direction, this behavioural pattern results in the species being subjected to changeable and often considerable advective forces which may act to carry the organisms away from the basins. Nevertheless, Boysen \& Buchholz (1984) showed that the population within a particular basin was autonomous and exhibited an uninterrupted lifehistory pattern, suggesting that the krill were able to counter the disruptive advective influences and maintain their preferred geographic position. However, a certain degree of immigration and emigration from the basins is still to be expected as a result of advective forces.

This study examines the vertical migration of the krill population within the Alkor Deep during a summer and a winter situation, primarily to characterise the relationship between these patterns and the physical environment and, secondarily, to consider the role of advective forces on distribution patterns. This approach allows advective displacement from a typical deep to be estimated and hence addresses the question of the metabolic cost of maintaining a preferred geographic location.

\section{Hydrography and bathymetry}

Circulation and currents - The Kattegat can be considered a large estuary with outflow of hyposaline Baltic water along the surface and inflow of seawater of nearly full salinity confined to the lower part of the water column in the deeper portion of the Kattegat. The strength and direction of currents are regulated by large-scale weather conditions and the distribution of barometric pressure over the North Sea and Baltic Sea. Under most wind conditions, there is a general northward flow at the surface and southward flow is confined to the deepest passages. Only when there are strong westerly and northerly winds are surface currents deflected southwards. 
Salinity - The circulation pattern normally results in Kattegat water being stratified with a halocline at ca. $10 \mathrm{~m}$ in the vicinity of the basin system. Above the halocline, values seldom exceed 20 psu and are generally lower during summer months. Below the halocline, salinities range between 30 and 34 psu for most of the year but are higher during the windy months of October and November (Buchholz \& Boysen, 1988).

Temperature - Temperature is extremely variable with depth and season. Surface waters range from more than $16{ }^{\circ} \mathrm{C}$ during summer to less than $1{ }^{\circ} \mathrm{C}$ during January and February (Buchholz \& Boysen, 1988). Steep temperature gradients and a difference of ca. $10^{\circ} \mathrm{C}$ exist between the surface and $80 \mathrm{~m}$ between June and November. Below $80 \mathrm{~m}$, seasonal temperatures are more constant and range between 5 and $10^{\circ} \mathrm{C}$.

Bathymetry - The Kattegat is mostly quite shallow, the average water depth being $27 \mathrm{~m}$. The Læsø Deep consists of a series of four depressions $<130$ m deep running north to south immediately to the east of the island of Læs $\varnothing$ (Ulrich, 1983). This study concentrates on the Alkor Deep, which is $3.5 \mathrm{~km}$ long, $1 \mathrm{~km}$ wide and runs in a NNE-SSW direction.

\section{Methods}

Sampling was carried out on board the R/V Heincke, a $55 \mathrm{~m}$ vessel equipped with a starboard winch and conducting cable for net deployments. This was used to operate a $1 \mathrm{~m}^{2}$ MOCNESS system with $2 \mathrm{~mm}$ mesh, flowmeter and temperature and salinity sensors. The net was deployed every $3 \mathrm{~h}$ over a $30 \mathrm{~h}$ period in a double oblique fashion. The ship passed over the Alkor Deep in a north-south plane at 2-3 knots, the direction depending on prevailing wind conditions.

Net 1 was sent down open and arrived at $80 \mathrm{~m}$ when the ship was over the rim of the basin. Net 2 was open between 80 and a maximum of $115 \mathrm{~m}$, depending on the exact course of the ship over the basin. Nets 3 to 8 were opened and closed every $20 \mathrm{~m}$ from $100 \mathrm{~m}$ to the surface, corresponding to ca. $5 \mathrm{~min}$ opening time. The last $20 \mathrm{~m}$ were sampled in $10 \mathrm{~m}$ intervals. Total deployment time was ca. 45 min which corresponded with the time taken for the ship to travel from one rim of the basin to the other.

Animals were immediately frozen at $-20^{\circ} \mathrm{C}$, then thawed on return to the laboratory where they were sexed, staged (Makarov \& Denys, 1980) and mea- sured in terms of carapace length. Carapace lengths were converted to total length and dry weight using calibrations taken from the same samples.

A $153 \mathrm{kHz}$ narrow-band ADCP (RD Instruments, San Diego, California) was deployed through the oceanographic well of the ship during each 30-h sampling period. The ADCP was set to collect data from 30 depth 'bins', each with a depth of $8 \mathrm{~m}$. Raw data were collected every ca. $1.5 \mathrm{sec}$ and averaged over six minutes to obtain current measurements, giving a standard deviation for each measurement of $0.83 \mathrm{~cm}$ $\mathrm{s}^{-1}$. The data were re-averaged over 30 -sec intervals for relative backscatter patterns in order to gain higher temporal resolution. Relative backscatter anomaly for each depth bin was calculated by subtracting an average value for the $30 \mathrm{~h}$ period from the mean value observed during each 3-hourly sampling period.

All times are given in local time (UTC +1 in winter; UTC +2 in summer).

\section{Results}

\section{Description of prevailing weather}

Summer situation - During the three days before sampling, wind direction was west-northwesterly, between 6 and $11 \mathrm{~m} \mathrm{~s}^{-1}$. During the 30-h sampling period, wind strength decreased from 12 to $2.7 \mathrm{~m} \mathrm{~s}^{-1}$ and shifted from northwesterly to northeasterly. As a result, surface currents would have been influenced to flow south against the prevailing northward current, slowing the outward-flowing Baltic current.

Winter situation - For two days prior to sampling, wind direction was northwesterly at ca. $12 \mathrm{~m} \mathrm{~s}^{-1}$. This shifted to south-southwesterly on the day before sampling at a speed of $11 \mathrm{~m} \mathrm{~s}^{-1}$. During sampling, wind direction drifted from west-northwesterly to southsouthwesterly and varied between 4 and $8.5 \mathrm{~m} \mathrm{~s}^{-1}$. The westerly wind would have acted against the northward flowing surface currents, although the effect would have been small given the low strength of the winds.

\section{Physical conditions over the Alkor Deep}

In the summer situation, there was a 3-layered temperature structure (Figure 2) which can be divided into surface, mid-layer and bottom. Between 0 and $16 \mathrm{~m}$, temperatures were approximately $15{ }^{\circ} \mathrm{C}$. In the midlayer $(17-50 \mathrm{~m})$ there was a steep temperature gradient 


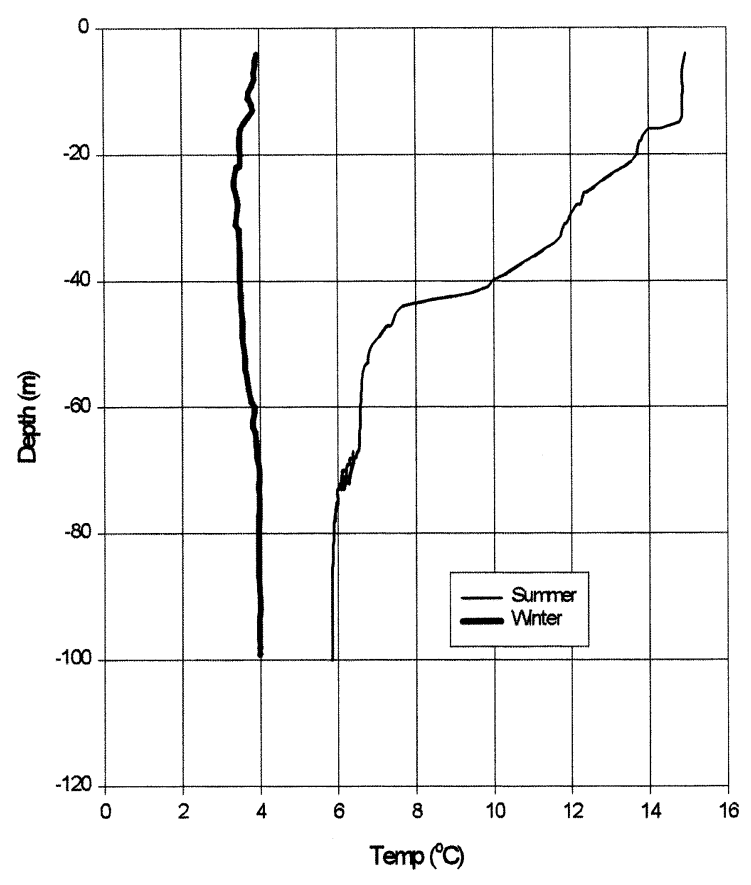

Figure 2. Temperature profile for the Alkor Deep in summer $(18 / 7 / 96)$ and winter (8/3/97).

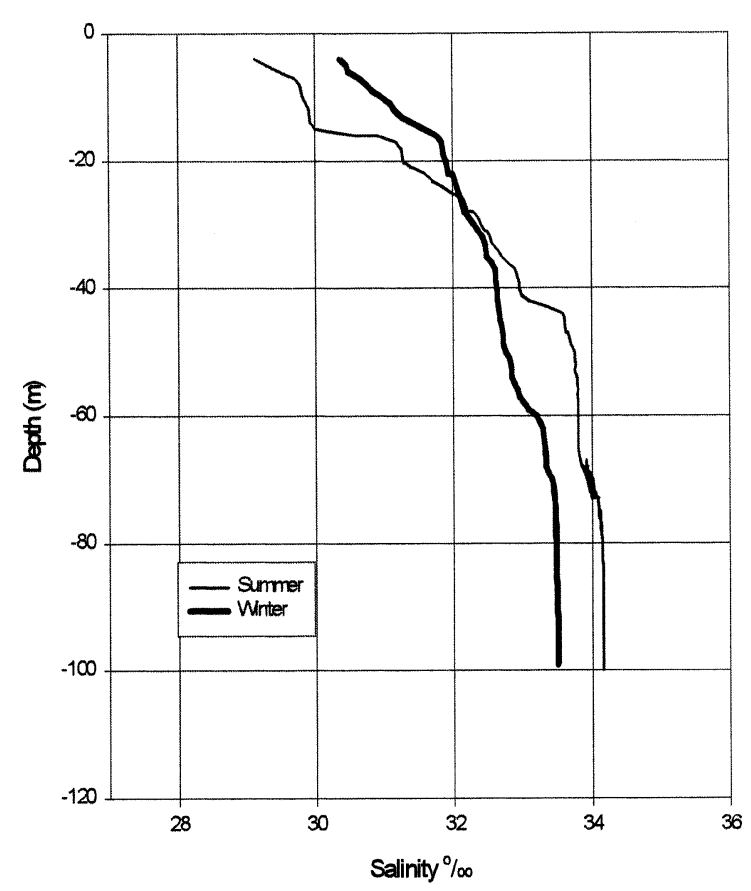

Figure 3. Salinity profile for the Alkor Deep summer (18/7/96) and winter $(8 / 3 / 97)$. where temperature dropped from $15^{\circ} \mathrm{C}$ to $7^{\circ} \mathrm{C}$. Below $50 \mathrm{~m}$, temperature was quite stable, falling gradually from $7^{\circ} \mathrm{C}$ to $6^{\circ} \mathrm{C}$ at $100 \mathrm{~m}$. By contrast, temperatures during the winter situation were virtually uniform throughout the water column at around $4{ }^{\circ} \mathrm{C}$.

The 3-layered structure in summer temperatures was mirrored in the salinity profiles (Figure 3), with quite stable values at the surface and bottom and a steep gradient in the mid-layer. Typical surface salinities were around $29 \mathrm{psu}$, rising to 33.5 psu down through the mid-layer and remaining around 33.534 psu between 50 and $100 \mathrm{~m}$. During the winter situation, salinities were generally higher than in summer between 0 and $30 \mathrm{~m}$ (30.4 psu as opposed to $29.1 \mathrm{psu}$ at $4 \mathrm{~m}$ in summer) but lower than in summer below $30 \mathrm{~m}$ (33.5 psu as opposed to $34.2 \mathrm{psu}$ at $90 \mathrm{~m}$ in summer); this illustrates a greater degree of mixing between fresh and marine inputs during the winter months. Nevertheless, there was still a 3-layered pattern as observed during summer with stable layers at the surface and bottom and a gradient in the mid-layer.

Figures 4 and 5 illustrate the strength and direction of currents with depth. Overall, there were three general patterns corresponding to the three layers identified in the T/S plots. In the summer situation, surface currents (at $16 \mathrm{~m}$ ) varied between $\mathrm{N}$ and $\mathrm{NE}$ and were between 5 and $15 \mathrm{~cm} \mathrm{~s}^{-1}$. In the mid-layer $(40 \mathrm{~m})$, currents were weaker (5 to $10 \mathrm{~cm} \mathrm{~s}^{-1}$ ) and more variable in direction compared with the upper layer, with a certain degree of tidal influence. For instance, between $15.00 \mathrm{~h}$ and $21.00 \mathrm{~h}$ on $18 / 7$ currents were to the east, corresponding with the low to high tide interval, whereas between $09.00 \mathrm{~h}$ and $15.00 \mathrm{~h}$ on 19/7 currents varied between NW and SW, corresponding with the high to low tide interval. Currents at $80 \mathrm{~m}$ were $\mathrm{S}$ to SSW in the range of $15-20 \mathrm{~cm} \mathrm{~s}^{-1}$.

In the winter situation, surface currents (at $16 \mathrm{~m}$ ) were $\mathrm{N}$ to $\mathrm{NW}$ between 15 and $30 \mathrm{~cm} \mathrm{~s}^{-1}$. The midlayer (at $40 \mathrm{~m}$ ) exhibited currents that were generally W to SW between 10 to $15 \mathrm{~cm} \mathrm{~s}^{-1}$ but there was also a weaker $S$ to $S E$ component with speeds around $5 \mathrm{~cm}$ $\mathrm{s}^{-1}$, which corresponded with the high to low tide interval. Currents at $80 \mathrm{~m}$ were variable, generally $\mathrm{S}$ to SW between 5 and $10 \mathrm{~cm} \mathrm{~s}^{-1}$ at most times but $\mathrm{N}$ to $\mathrm{NE}$ at 5 to $10 \mathrm{~cm} \mathrm{~s}^{-1}$ between $19.00 \mathrm{~h}$ and $02.00 \mathrm{~h}$ on $18 / 7$.

Overall, surface currents were strong and predominantly to the north throughout both sampling periods, corresponding to the brackish Baltic outflow. The flow of this surface current was probably retarded in summer and in winter by a northerly and a westerly current 


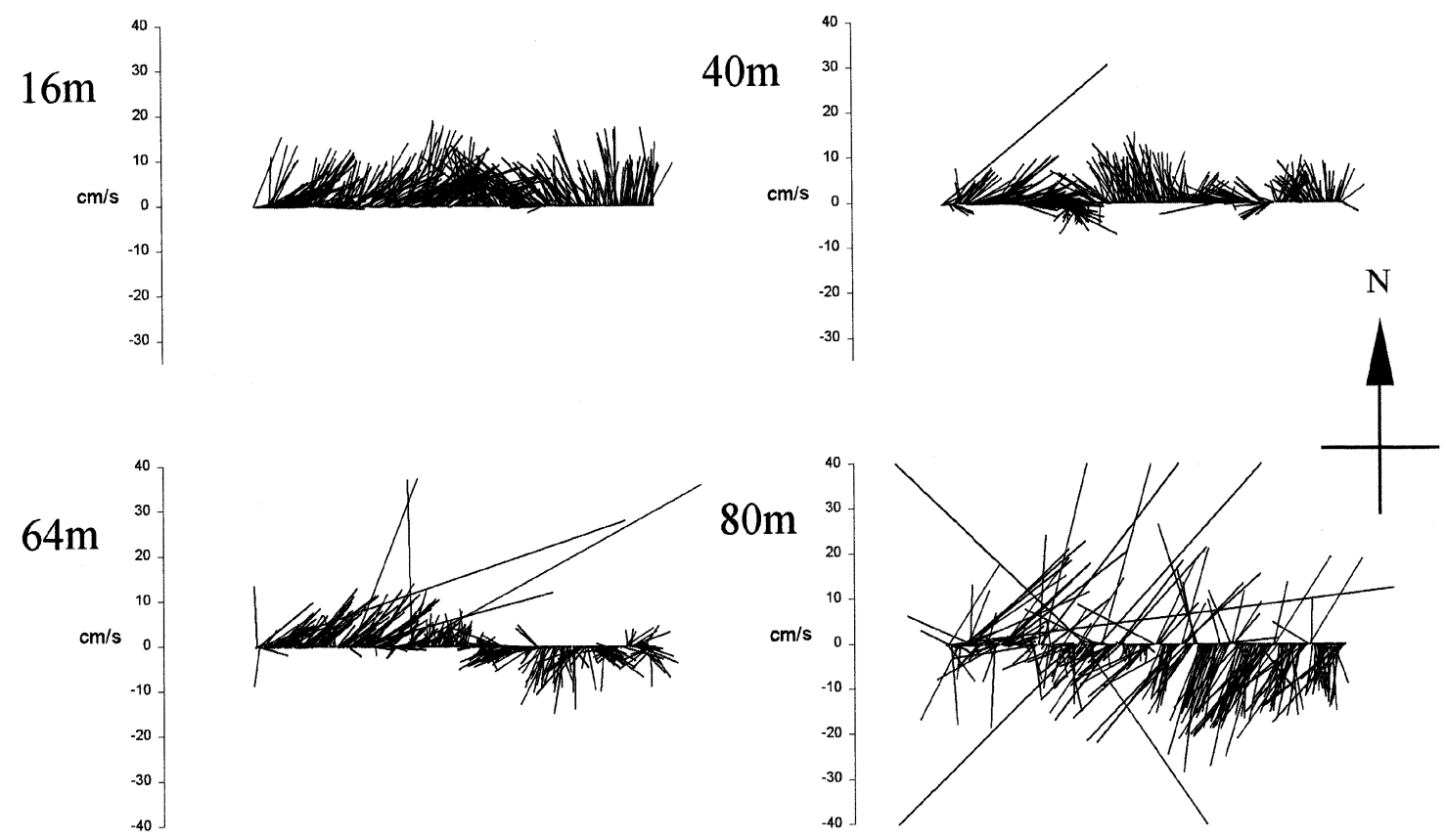

Figure 4. Current strength and direction during a $30 \mathrm{~h}$ period over the Alkor Deep in summer (18-19/7/96).
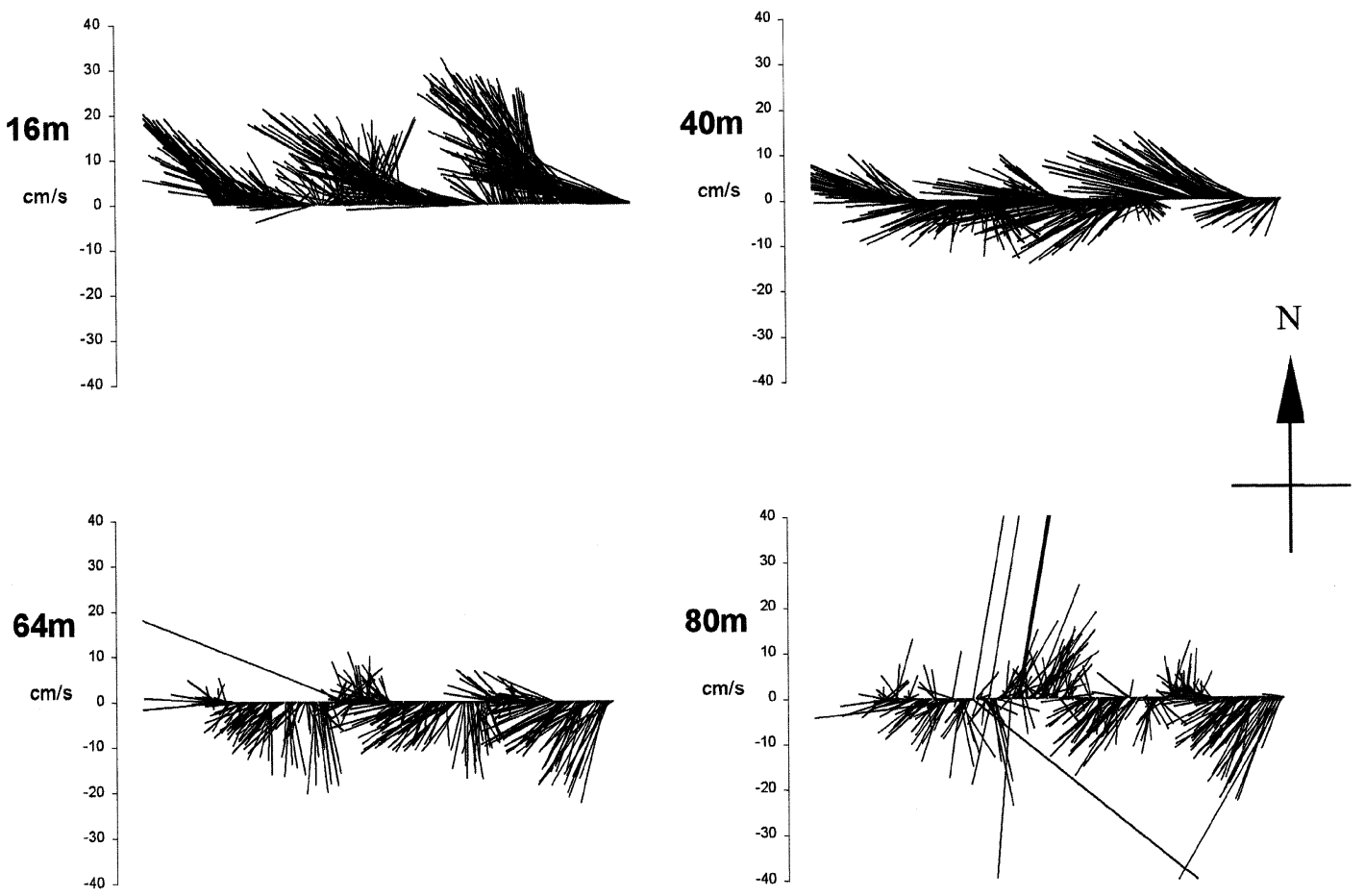

Figure 5. Current strength and direction during a $30 \mathrm{~h}$ period over the Alkor Deep in winter (8-9/3/97). 


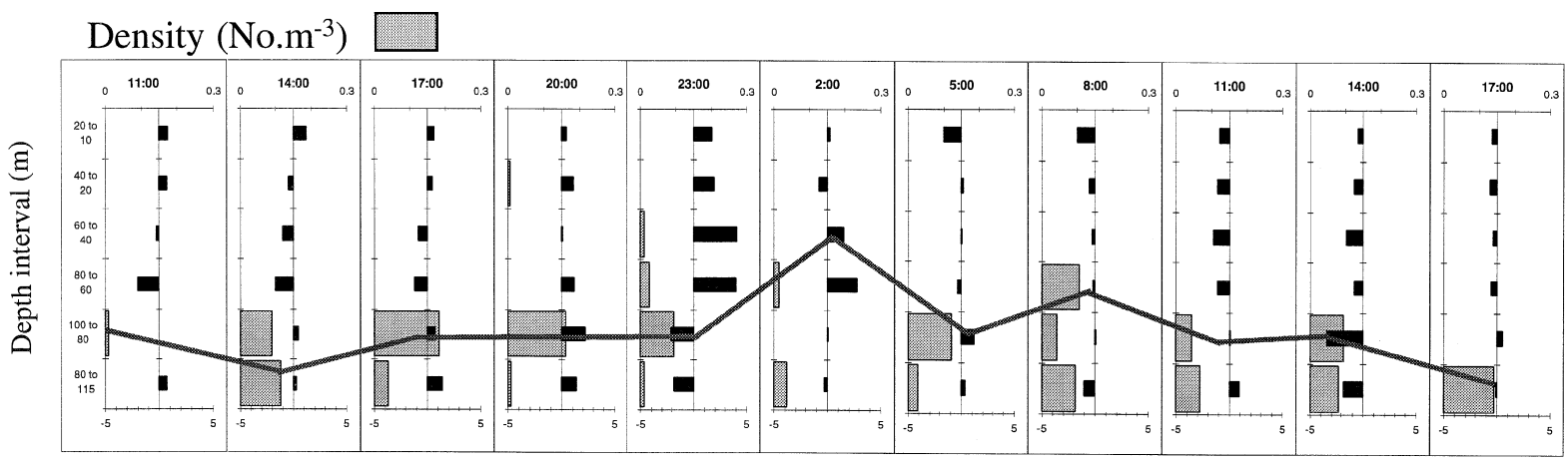

Relative backscatter anomaly $(\mathrm{dB})$

Vertical movement of average krill

Figure 6. Density (grey) and relative backscatter anomaly (black) of krill through the water column during a $30 \mathrm{~h}$ period in summer.

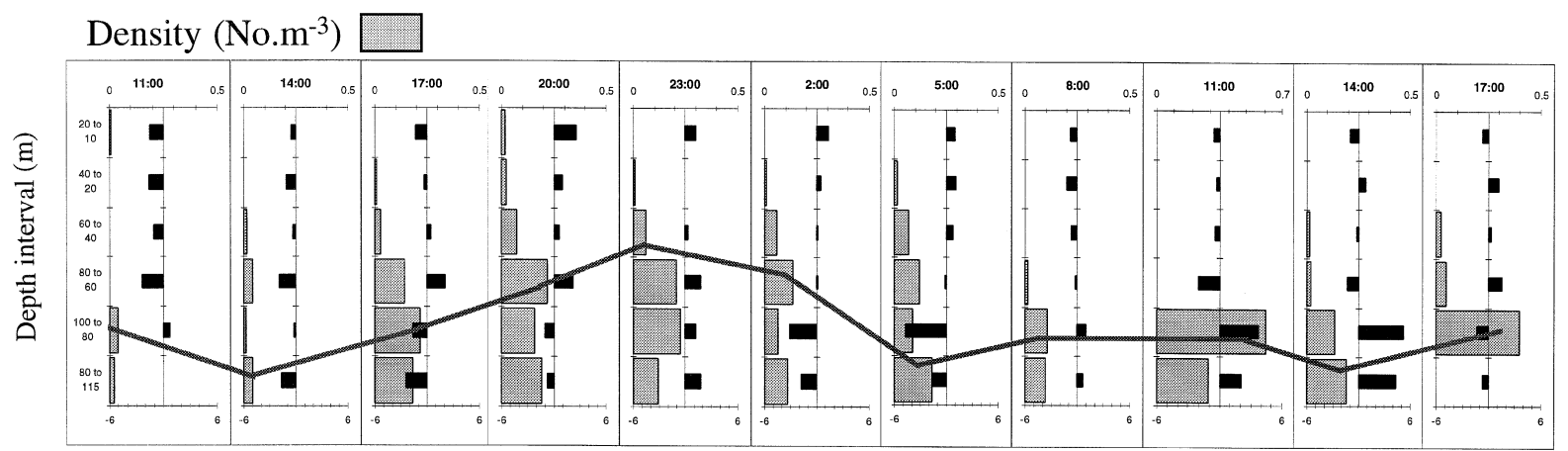

Relative backscatter anomaly $(\mathrm{dB})$

Vertical movement of average krill

Figure 7. Density (grey) and relative backscatter anomaly (black) of krill through the water column during a $30 \mathrm{~h}$ period in winter.

respectively. Bottom currents were predominantly to the south and conformed to the marine inflow from the Skagerrak. Greater variability of the bottom current in the winter may have been a result of increased mixing between layers during the winter months. Currents in the intermediate layer were variable and tidally influenced, representing the transition between the contrasting flow regimes.

\section{Biological patterns}

A full description of the net catches is given by Tarling et al. (submitted) and only a brief resumé of the general patterns will be given here. The densities of krill were lower during the summer period compared with winter, $\left(0.0267-3.46\right.$ ind $\mathrm{m}^{-2}$ compared with $0.82-10.05$ ind $\mathrm{m}^{-2}$ ), but in both seasons the krill characteristically concentrated within the basin during the day and ascended during the night (Figures 6 and 7). In summer, low densities were detected between 40 and $80 \mathrm{~m}$ at 23.00 and $02.00 \mathrm{~h}$ whilst densities within the basin decreased. In winter, density decreases within the basin were observed over a longer period $(02.00 \mathrm{~h}$ to $11.00 \mathrm{~h})$ and animals were regularly found between 20 and $40 \mathrm{~m}$ from $17.00 \mathrm{~h}$ to $05.00 \mathrm{~h}$. The size distribution of the populations found during summer and winter corresponded with a previous study of the annual cycle of the Kattegat population (Boysen \& Buchholz, 1984), with a unimodal distribution (peak at $30 \mathrm{~mm}$ total length) in summer and a bimodal distribution (peaks at 23 and $30 \mathrm{~mm}$ total length) in winter. Smaller animals tended to migrate vertically more than larger animals in winter but no such tendency was evident in summer.

Backscatter patterns (see Tarling et al., submitted) and net catches were used jointly to interpret the typical vertical migration of the krill population over a diurnal cycle in summer and in winter. Figures 6 and 7 show the percentage distribution in the net samples 
(grey histograms) and the backscatter anomalies for each ADCP depth bin (black histograms) throughout the sampling period; the line superimposed on this double set of histograms is an attempt to estimate the 'typical' vertical movement of a hypothetical krill through the whole sampling period. In most cases, the position of this line has largely been determined by the distribution in the net samples, but at night, when there were high positive ADCP anomalies at 40-60 and $60-80 \mathrm{~m}$ and net catches were small (presumably the result of dispersion away from the vicinity of the basin) more weight has been given to the backscatter results. The vertical movement so derived has then been related to ADCP data on the strength and direction of currents through the water column, in order to estimate the influence of horizontal advective forces on the krill. Figure 8 depicts the horizontal displacement, at 6-min intervals, of a passive particle following the same vertical movements of a hypothetical krill. During each 6-min period, the particle is advected by the horizontal current values for the appropriate depth and time, and moved to a new coordinate. This co-ordinate then becomes the starting point for the next 6-min period such that each movement is cumulative. The starting point for the particle was the centre of the Alkor Deep and the calculation was carried out for the 30 -h period covered by the net sampling series.

The calculation showed that a passive particle in summer would be advected towards the S or SW, with the deep southward flowing Skaggerak water being a major influence. After $30 \mathrm{~h}$, the particle would have travelled $3230 \mathrm{~m}$ from the middle of the basin. This would mean that an individual would have to maintain an average speed of $3.0 \mathrm{~cm} \mathrm{~s}^{-1}$ in order to remain within the Alkor Deep. During winter, nett advection would be to the WSW, because of the greater influence of the mid-layer current on the population as a result of the longer period of time it spends in that layer. The nett distance transported from the deep would have been $3440 \mathrm{~m}$ in $30 \mathrm{~h}$, implying that an individual would have to maintain a speed of $3.2 \mathrm{~cm} \mathrm{~s}^{-1}$ in order to retain its original position.

\section{Cost of a pelagic lifestyle in the Kattegat}

Work carried out by Kils (1981) showed that, in the case of Euphausia superba, animals may swim between speeds of between 0 and $15 \mathrm{~cm} \mathrm{~s}^{-1}$ without affecting their 'standard metabolism'. This is because, within this range, krill regulates its speed mainly by

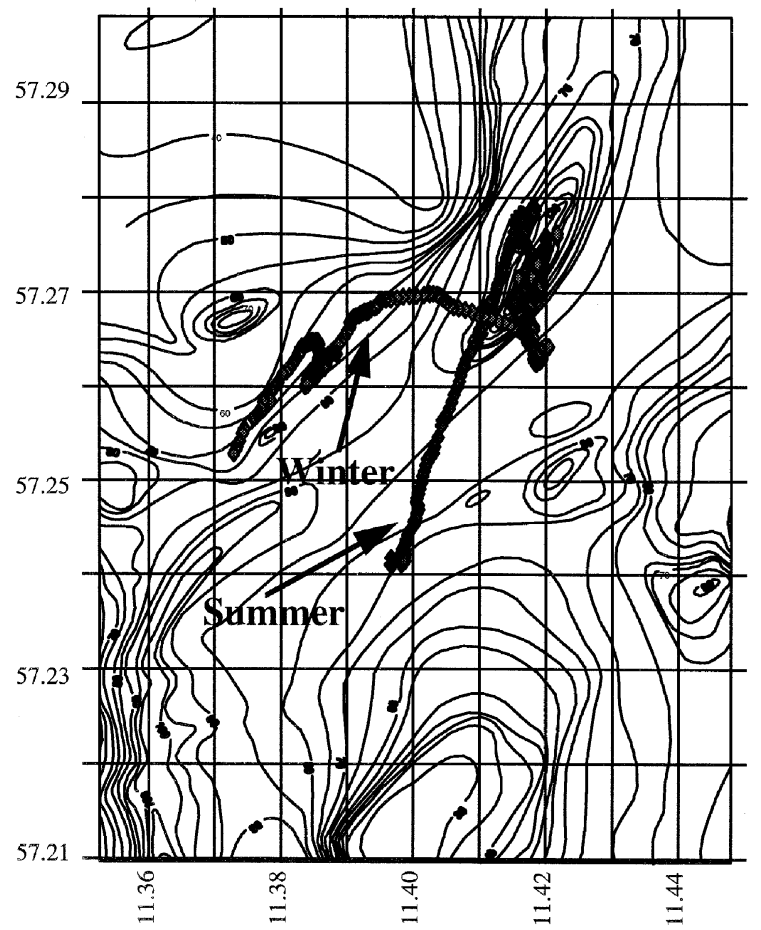

Figure 8. Horizontal displacement of a passive particle following the same vertical movements as a hypothetical krill over $30 \mathrm{~h}$ in summer and winter.

changes in the execution of the pleopod swimming stroke. At $15 \mathrm{~cm} \mathrm{~s}^{-1}$, the pleopod stroke is optimally executed. Between 15 and $40 \mathrm{~cm} \mathrm{~s}^{-1}$, the frequency of strokes controls the speed which would in turn increase the metabolic rate to an 'active metabolism'. Although similar experiments have not been carried out as comprehensively on Meganyctiphanes, it is believed that similar values would apply because the reduction in propulsive force from the pleopods would be counteracted by a corresponding decrease in the resistance of the body moving through water, since both parameters are a function of surface area. For the purposes of this investigation, therefore, one can conclude that the speeds Meganyctiphanes needs to achieve in order to remain within the vicinity of the Alkor Deep over a diurnal cycle are well within its capabilities and do not require the animal to increase its metabolic rate above the 'standard' level.

Further data provided by Kils (1981) allow the approximate daily costs of Meganyctiphanes maintaining a pelagic lifestyle to be calculated. One way this can be estimated is by considering what distance an organism would have sunk in a given time and hence, what 'performance' $\left(\mathrm{P}, \mathrm{J} \mathrm{d}^{-1}\right)$ is demanded of 
Table 1. Comparative metabolic requirements for different sizes of krill found in the alkor depression swimming at $3 \mathrm{~cm} \mathrm{~s}^{-1}$.

\begin{tabular}{|c|c|c|c|}
\hline $\begin{array}{l}\text { Length } \\
(\mathrm{mm})\end{array}$ & $\begin{array}{l}\text { Underwater } \\
\text { weight } \\
(\mathrm{mg})\end{array}$ & $\begin{array}{l}\text { ATP requirement } \\
\text { for pleopod } \\
\text { muscles } \\
\left(\mu \text { mol ind }^{-1} \mathrm{~d}^{-1}\right) \\
\text { Estimate } 1\end{array}$ & $\begin{array}{l}\text { ATP proportion } \\
\text { of standard } \\
\text { metabolism for } \\
\text { swimming } \\
\left(\mu \text { mol ind }{ }^{-1} \mathrm{~d}^{-1}\right) \\
\text { Estimate } 2\end{array}$ \\
\hline 22 & 13.8 & 2.3 & 27.8 \\
\hline 25 & 22.5 & 4.2 & 36.8 \\
\hline 30 & 45.2 & 10.2 & 67.5 \\
\hline
\end{tabular}

the swimming muscles to prevent such sinking. The sinking distance is a function of the underwater weight of an animal, the sinking speed and gravitational force. The underwater weight of Meganyctiphanes increases with length to the power 3.76, whilst sinking speed increases linearly with length. Hence, larger animals demand a significantly higher performance from their swimming muscles than smaller animals in order to remain buoyant. To give some idea of the comparative costs within a typical krill population found in the Alkor Deep, the metabolic demand for maintaining buoyancy has been calculated for three common size classes at the time of the winter survey, $22 \mathrm{~mm}, 25 \mathrm{~mm}$ and $30 \mathrm{~mm}$ :

$$
P=m \cdot g \cdot h \cdot t^{-1},
$$

where:

$P=$ performance $\left(\mathrm{J} \mathrm{d}^{-1}\right)$

$m=$ underwater weight $(\mathrm{kg})$

$g=$ earth acceleration $\left(\mathrm{m} \mathrm{s}^{-2}\right)$

$h=$ sinking distance per second $(\mathrm{m})$

$t=$ time unit (s)

From equations given in Kils (1981), this can be reduced to

$$
P=6.54 \cdot 10^{-9} \cdot L^{-4.83},
$$

where:

$L=$ length (mm)

Performance $\left(\mathrm{J} \mathrm{d}^{-1}\right)$ can be converted into the amount of ATP that must be provided to the pleopod swimming muscles by assuming that the conversion efficiency of muscles is $25 \%$ and that $1 \mathrm{~mol} \mathrm{ATP}^{-} 35 \mathrm{~kJ}$ (see Table 1, Estimate 1).

Another approach is to compare the metabolic rates of an animal during swimming and resting. Since krill do not exhibit typical resting behaviour comparisons have to be made with a species that does. The shrimp, Crangon crangon, shows resting, burrowing and swimming (hovering) behaviour, and it has been shown that its metabolic rate increases by $60 \%$ whilst hovering (Kils, 1981). To apply to Meganyctiphanes however, further parameters need to be applied to this value, as will be outlined. Within the Alkor Deep, krill must swim at $3 \mathrm{~cm} \mathrm{~s}^{-1}$ in order to maintain their geographic position (see above). Swimming at this speed creates a significant amount of hydrodynamic uplift which would counteract the underwater weight and hence the sinking force. In Euphausia superba, animals swimming at $3 \mathrm{~cm} \mathrm{~s}^{-1}$ had a body angle of $30^{\circ}$ which created an uplift that was $29 \%$ of the sinking force. Observations of Meganyctiphanes made by Kils (1981) suggest that the relationship between body angle and speed are approximately the same but with higher standard deviation. The proportion of krill metabolism used in swimming would therefore be approximately $40 \%$ of the total metabolism (i.e. $(100-29) \%$ of $60 \%)$. Respiration rates for $30 \mathrm{~mm}$ krill from the Alkor deep were measured at $1.1 \mathrm{mg}$ $\mathrm{O}_{2} \cdot \mathrm{g}_{d}{ }^{-1} \cdot \mathrm{h}^{-1}$ (Saborowski, unpubl.data; $\mathrm{g}_{d}-$ dry weight ( $\mathrm{g}), \mathrm{h}$ - hour) which can, in turn, be converted to ATP production during swimming (see Table 1, Estimate 2).

The first estimate of swimming represents an underestimate of true swimming costs, since during the passing on of energy through the pleopod muscles to the water, a certain amount will be lost. The second estimate is certainly higher than reality since krill are far more efficient swimmers than Crangon crangon. Hence the true value for carrying out a pelagic lifestyle in the Kattegat should be between these two values.

\section{Discussion}

Comparing MOCNESS net catches with ADCP backscatter patterns may be subject to two main errors (Pieper, 1979): variability in backscattering strength for a given euphausiid biomass, and differences inherent in the two sampling methods. As Cochrane et al. (1994) discovered when using a bottom-mounted ADCP over a 49-d period, day and night backscattering strength may vary, probably as a result of different angles of orientation of the animals. When the decrease in backscatter during the period of upward swimming was related to target-strength models by Cochrane et al. (1994), results indicated that the 


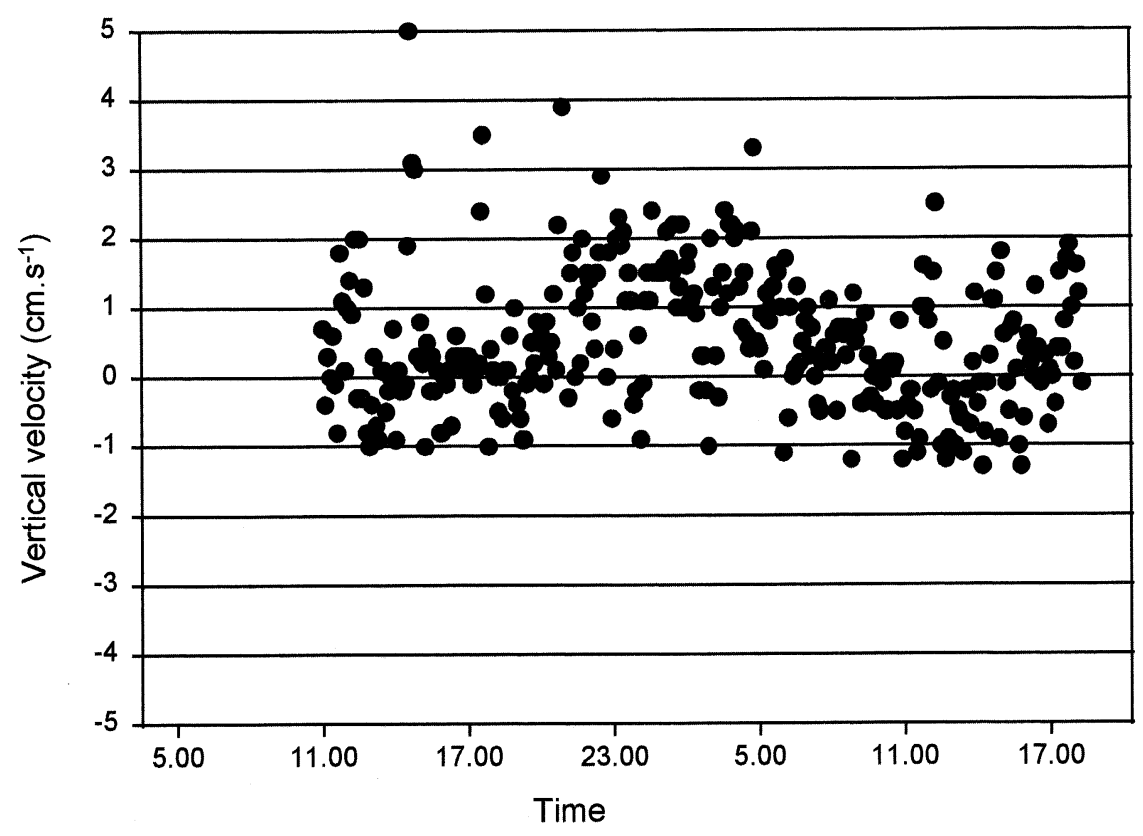

Figure 9. Vertical velocities $\left(\mathrm{cm} \mathrm{s}^{-1}\right)$ measured at $80 \mathrm{~m}$ over $30 \mathrm{~h}$ during summer (18-19/7/96) [-ve downwards; +ve upwards].

organisms probably changed their orientation from horizontal to $30^{\circ}$. This fits well with the prediction by Kils (1981) that the propulsive force necessary for upward lift is minimised at body angles of around 20$30^{\circ}$. In relation to the present study, such variability in backscattering is small compared with the larger distributional changes seen diurnally and probably does not mask any general pattern. Correspondence between the ADCP and the MOCNESS is more of a problem since krill populations are known to be patchy and currents may deflect the path of the net over the basin in relation to the swath of the shipboard ADCP. Tarling et al. (submitted) consider the correlation between net samples and relative backscatter in both the summer and winter situations and conclude that backscatter data may be used to complement information gained from net catches. For instance, very little krill was caught in the upper layers, or indeed in the lower layers, during night-time in the summer, but the ADCP did show higher backscatter from the upper layers at this time, indicating that krill did occur there and may have dispersed horizontally.

Data collected by ADCPs allow the vertical velocity of backscattering particles to be measured directly. Assuming there is no significant upwelling or downwelling, this can provide estimates of vertical migration speeds that can be compared with data from net catches and the movement of backscatter- ing bands over time. The nature of krill distributions during this study made estimates of vertical migration speed from net catches and backscattering data difficult, because the krill did not ascend in discrete bands but dispersed during the night. Therefore, the vertical velocity component derived from the ADCP is the most valid method of estimating vertical migration speeds in this instance. Figure 9 shows vertical velocities observed in the layer of highest krill densities $(80 \mathrm{~m})$ in summer. Although there is variability in the measurements, a higher proportion of upward velocities were observed between 23.00 and $02.00 \mathrm{~h}$ whilst a greater proportion of downward velocities occurred during daytime. Since Meganyctiphanes is one of the main backscattterers (Figures 6 and 7), it is plausible that this species was a major contributor to this diurnal pattern. Upward velocities averaged around $2 \mathrm{~cm} \mathrm{~s}^{-1}$ whilst downward velocities averaged around $1 \mathrm{~cm} \mathrm{~s}^{-1}$. These velocities are slightly below estimates from other studies of the vertical velocity of Meganyctiphanes, both from ADCP data (Buchholz et al., 1995 $-3 \mathrm{~cm} \mathrm{~s}^{-1}$, Cochrane et al., $1994-2.8 \mathrm{~cm} \mathrm{~s}^{-1}$, Cochrane et al., $1991-4 \mathrm{~cm} \mathrm{~s}^{-1}$, Heywood, $1996-2$ to $\left.6 \mathrm{~cm} \mathrm{~s}^{-1}\right)$ and from observations made in the laboratory (Hardy \& Bainbridge, $1954-2.5 \mathrm{~cm} \mathrm{~s}^{-1}$ over a $100 \mathrm{~m}$ interval upwards, $3.6 \mathrm{~cm} \mathrm{~s}^{-1}$ downwards over $130 \mathrm{~m}$ ). The ADCP averages any detected movement over 6-min periods in order to reduce the otherwise 
large standard deviation; thus the speed of migrating organisms will be combined with those of stationary particles within a particular depth/time bin. Estimates of vertical migration become more accurate as the ratio of moving to stationary particles becomes greater. In this instance, densities of krill were relatively low, so estimates of the speed of vertical migration are probably underestimated.

The winter-time observation that a number of krill remained in the Alkor Deep during nighttime suggests one of two things: either krill may ascend and descend for brief periods every night and different individuals ascend at different times, or a fraction of the population does not ascend every night. The first scenario is feasible given that krill can ascend at a rate of $2 \mathrm{~cm}$ $\mathrm{s}^{-1}$ at least (see above) equivalent to $72 \mathrm{~m}$ in one hour. Furthermore, Gibbons (1992) has shown by analysis of stomach contents that asynchronous migration does occur in Euphausia lucens. However, this behaviour has yet to be demonstrated in M. norvegica. In the Skagerrak, Bergström \& Strömberg (1996) found high numbers of Meganyctiphanes remaining at depth at night, suggesting that the second scenario applied in that case. Assuming this can also occur in the Kattegat, one could predict the frequency of ascent to the upper levels over a period of several days, by comparing the relative densities of the day and night populations within the basin. For example, during winter, when catches were larger, the ratio of day to night densities was 3 to 1 , suggesting that one third of the population remained at depth every night and that perhaps any one individual made an ascent on two out of every three days. To gain a more accurate estimate, one would need to consider the variability in day and night densities over an extended period.

Any differences in the frequency of ascent and the depth distribution of the various size classes may be related to the disproportionate increase in underwater weight with size, as described by Kils (1981) and illustrated in Table 1: a $25 \mathrm{~mm}$ krill only has to combat $50 \%$ of the underwater weight of a $30 \mathrm{~mm}$ krill and a $22 \mathrm{~mm}$ krill only $30.5 \%$. Converting this into ATP requirements, a $25 \mathrm{~mm}$ krill would need to provide between 41 and $54 \%$ of that necessary for a $30 \mathrm{~mm}$ krill if it is to maintain a pelagic lifestyle and a $22 \mathrm{~mm}$ krill between 22 and $40 \%$. These values represent the costs of hovering, not of vertical migration; in order to ascend, an individual must change its orientation so that a greater propulsive force goes into the vertical vector rather than the horizontal. This, in turn, would result in a decrease in the horizontal vector and hence a loss of speed. In order to maintain location within the Alkor Deep, therefore, both a change in angle and an increase in propulsive force would be necessary. The cost of these actions would also vary with size, both with respect to the resistance of a body facing a stream of water, which scales as $\mathrm{L}^{2}$ and with respect to underwater weight, which scales as $\sim \mathrm{L}^{4}$. It would not, therefore, be surprising to find that large individuals ascend less frequently than small ones.

Overall, it appears that krill are capable of withstanding the advective forces experienced within the Læsø Deep system and their activity does not necessitate raising their metabolic activity above a 'standard' rate. Behavioural changes with size would be expected from calculations made of the relative costs of swimming behaviour, such that larger individuals would migrate over a smaller vertical range and/or less frequently. Further analyses of the population dynamics and size-specific depth distributions are necessary to address this hypothesis.

\section{Acknowledgements}

We would like to thank the following people for their assistance in collecting net samples during the summer and winter missions: S. Bröhl, P. Schumann, K. Grau, M. Salomon, Dr D. Müller-Navarra, E. Alberssard, Dr J.-P. Labat, Dr S. Dallot, Dr A. Bedo, Dr J. CuzinRoudy, Dr P. Mayzaud, Dr P David and Dr O. Guerin. In particular, we are grateful for the efforts of S. Bröhl in collecting length-weight measurements and helping in respiration experiments. Finally, we would like to acknowledge the support and efficiency of the crew of the $R / V$ Heincke during both missions. This project was funded by EU-MAST III (MAS3-CT-0013), The PEP-Programme.

\section{References}

Bergström, B. \& J.-O. Strömberg, 1997. Behavioural differences in relation to pycnoclines during vertical migration of the euphausiids Meganyctiphanes norvegica (M. Sars) and Thysanoessa raschii (M. Sars). J. Plankton Res. 19: 255-261.

Boysen, E. \& F. Buchholz, 1984. Meganyctiphanes norvegica in the Kattegat. Mar. Biol. 79: 195-207.

Buchholz, F. \& E. Boysen-Ennen, 1988. Meganyctiphanes norvegica (Crustacea: Euphausiacea) in the Kattegat: studies on the horizontal distribution in relation to the hydrography and zooplankton. Ophelia 29: 71-82.

Buchholz, F., C. Buchholz, J. Reppin \& J. Fisher, 1995. Diel vertical migrations of Meganyctiphanes norvegica in the Kattegat: Comparison of net catches and measurements with Acoustic Doppler Current Profilers. Helgolander wiss. Meeresunters. 49: 849-866. 
Cochrane, N. A., D. Sameoto, A. W. Herman \& J. Neilson, 1991 Multiple-frequency acoustic backscattering and zooplankton aggregations in the inner Scotian Shelf basins. Can. J. Fish. aquat. Sci. 48: 340-355.

Cochrane, N. A. \& D. D. Sameoto, 1994. Temporal variability of euphausiid concentrations in a Nova Scotia shelf basin using a bottom-mounted acoustic Doppler current profiler. Mar. Ecol. Prog. Ser. 107: 55-66.

Einarsson, H., 1945. Euphausiacea I. Northern Atlantic Species Dana Report 27: 1-184

Gibbons, M. J., Vertical migration and feeding of Euphausia lucens at two $72 \mathrm{~h}$ stations in the southern Benguela upwelling region. Mar. Biol. 116: 257-268.

Hardy, A. C. \& R. Bainbridge, 1954. Experimental observations on the vertical migrations of planktonic animals. J. mar. biol. Ass U.K. 33: 409-448.

Heywood, K. J., 1996. Diel vertical migration of zooplankton in the Northeast Atlantic. J. Plankton Res. 18: 163-184.

Kils, U., 1981. Swimming behaviour, swimming performance and energy balance of Antarctic krill Euphausia superba. BIOMASS Scientific Series 3: $121 \mathrm{pp}$.

Lindley, J. A., 1982. Population dynamics and production of euphausiids III. Meganyctiphanes norvegica and Nyctiphanes couchii in the north Atlantic ocean and the North Sea. Mar. Biol. 66: $37-46$.
Makarov, R. R. \& C. J. Denys, 1980. Stages of sexual maturity of Euphausia superba. BIOMASS Scientific Series 11: 13 pp.

Mauchline, J. \& L. R. Fisher, 1969. The biology of euphausiids. Adv. Mar. Biol. 7: 1-454.

Mauchline, J., 1980. The biology of mysids and euphausiids. Adv. Mar. Biol. 18: 1-681.

Nicol, S., 1986. Shape, size and density of daytime swarms of the euphausiid Meganyctiphanes norvegica in the Bay of Fundy. Mar. Ecol. Prog. Ser. 18: 241-251.

Pearcy, W. G., C. C. E. Hopkins, S. Grønvik \& R. A. Evans, 1979. Feeding habits of cod, capelin and herring in Balsfjorden, northern Norway, July-August 1978: the importance of euphausiids. Sarsia 67: 269-277.

Pieper, R. E., 1979. Euphausiid distribution and biomass determined acoustically at $102 \mathrm{kHz}$. Deep Sea Res. 26: 687-702.

Pleuddemann, A. J. \& R. Pinkel, 1989. Characterization of the patterns of diel migration using a Doppler sonar. Deep Sea Res. 36: 509-530.

Ulrich, V. J., 1983. Zur Bathymetrie und Topographie der nördlichen Kattegat-Rinne. Meeresforsch. 30: 61-68. 
